\title{
Sizing methodology for photovoltaic systems considering coupling of solar energy potential and the electric load: dynamic simulation and financial assessment
}

\author{
Juan José Milón Guzmán ${ }^{1, *}$, Sergio Leal Braga ${ }^{2}$, Juan Carlos Zúñiga Torres ${ }^{1}$, and Herbert Jesús Del Carpio Beltrán ${ }^{1}$ \\ ${ }^{1}$ Universidad Tecnológica del Perú, Peru \\ ${ }^{2}$ Pontifícia Universidade Católica do Rio de Janeiro, Brasil
}

\begin{abstract}
A reliable methodology for the dimensioning of photovoltaic systems is presented in this paper. This method generates technical-financial variables that aid in the choice of the most adequate photovoltaic power system for each project. The techniques that are usually used determine the size of PV power plants considering the monthly average of the solar energy potential of the month with the lowest solar radiation and the electricity to be supplied to satisfy the demand. These conventional techniques generate an uncertainty of at least $40 \%$, mainly due to the daily dispersion of the solar energy availability and of the electric load. The proposed methodology takes into account a region's own photovoltaic energy potential and the detailed characteristics of the electric load, matching both with different PV power plants sizes, and analyzing the whole during a time period that guarantees the reliability of the results. The energy coupling is performed integrating the energy parameters (solar energy and electric load) in short time intervals (30 minutes maximum) to determine the supplied energy, the unsupplied energy demand and the unused solar energy. The daily integration of the three factors, using a dynamic simulation and performing a financial evaluation, allows for the identification of the most appropriate PV power plant size for every project. The results indicate that this methodology reduces the uncertainty of the solar power-electric load coupling from $40 \%$ to $2.2 \%$, which allows a better definition of the financial variables that determine the most appropriate installed solar power for a photovoltaic project.
\end{abstract}

\section{Introduction}

Today, different methodologies to size photovoltaic (PV) systems exist. They allow the calculation of technicalfinancial parameters to improve the possibilities of using this energy source. The available tools are commercial software, spreadsheet templates and mobile applications. The decision of investing in a photovoltaic installation is driven mainly by financial factors, like the payback period, which is calculated based on the technical characteristics of the system and ideal-condition values for factors such as inclination, orientation, solar radiation, electric load, etc. Most of the existing methodologies, suggest using critical low values of solar irradiance and high average values of electric load for the calculation, which results in an oversizing that guarantees the operation of the PV system in any condition [1]; however, this results in a surplus of unused photovoltaic electricity, a higher initial investment cost and finally a longer than expected payback period. The sizing of a PV systems begins with the selection of the most important components: the PV panels, controllers, inverters, and accessories [2][3] that will be used in particular geographical conditions, where solar energy is available and an electric load has to be fed. Moreover, some methodologies include a forecast of the energy demand, the characterization of the photovoltaic potential on the geographical location, and consider different storage technologies [4]. Storage systems significantly increase the costs of PV systems, nevertheless they are an important factor for isolated areas or locations where the network offers low electric power quality. In these places, the sizing of PV systems would depend strongly on the additional cost of batteries and the reliability required from the system during energy outages [5] [6] [7] [8] [9], even in shared storage systems [10].

Lately, genetic algorithms are being used as a tool to optimize the sizing of PV panels and the battery system, with the aim of maximizing the economic benefit obtained from the use of the system in different scenarios [11][12]. Since PV energy can be an adequate complement for so-called hybrid systems, some techniques have been developed for optimizing the sizing and cost analysis of hybrid PV/wind systems [13][14], or more complex $\mathrm{PV} /$ wind/hydrogen systems plus batteries $[15][16]$, the sizing being a more complex and less reliable process. Sizing methodologies are applied also for specific loads such as the ones of photovoltaic solar pumping systems: since the load is constant, the sizing of the system is eased, whether or not the system is

* Corresponding author: jmilon@utp.edu.pe 
connected to the network [17][18]. In some cases, the information of the solar potential available in a specific region is used to estimate the electricity cost reduction (in urban areas) or the energy supply (in rural areas) [13][19]. All sizing methodologies for PV systems consider technical and financial aspects that allow the use of this renewable technology, however, some aspects are not considered concerning small scale PV applications, like residential use, where the benefits of the investment are not reflected in the daily consumption [20].

One of the keys to reduce the payback period of PV installations is to reduce unused solar energy (surplus), especially when it cannot be injected into the grid because it is generated in an isolated system or due to the lack of a legal framework for its sale in the country. In many cases, the payback period for PV systems is doubled because the production surpluses are not economically exploited, even though some techniques for the generation of heat with PV electricity surpluses exist [21].

In the literature review, much information has been found for a correct sizing of the components of photovoltaic systems, however, none of them propose energy coupling between solar power and the electric load for the sizing of a PV system. Thus, this paper presents a methodology for PV systems sizing considering the coupling of the potential of solar energy and the electrical load through a dynamic simulation and financial evaluation.

\section{Proposed methodology}

The most important concepts to perform an energy assessment for a solar photovoltaic project are shown in Figure 1. Available solar power and demand never match perfectly, which does not allow the use of all the solar energy available and the fulfillment of the electricity demand. Nowadays, it is widely believed that to better harness solar energy, energy has to be produced and used immediately [18]. For grid-connected PV systems, all the produced energy is injected to the system, but for isolated PV systems, a percentage of the energy is not used. This unused energy has to be reduced as much as possible while avoiding the perturbation of the electricity supply.

The proposed methodology determines the best match between solar power and electric load, defining the installed solar power that fulfills the maximum demand and reduces the unused solar power. This simulation is performed for different PV power plant sizes until the best option is found (in energy and financial terms). To guarantee the reliability of the results it is necessary to have the electric load characteristics and data and the solar radiation of the months that are considered for the conventional calculation. The rate of acquisition (solar energy and electric load) of the data used must be short (between 15 and 60 minutes).

Fig. 1 shows that the methodology is based on direct electricity supply during daylight hours, which means that the solar energy is transformed and consumed immediately. The storage of photovoltaic solar energy for nighttime hours is not considered.

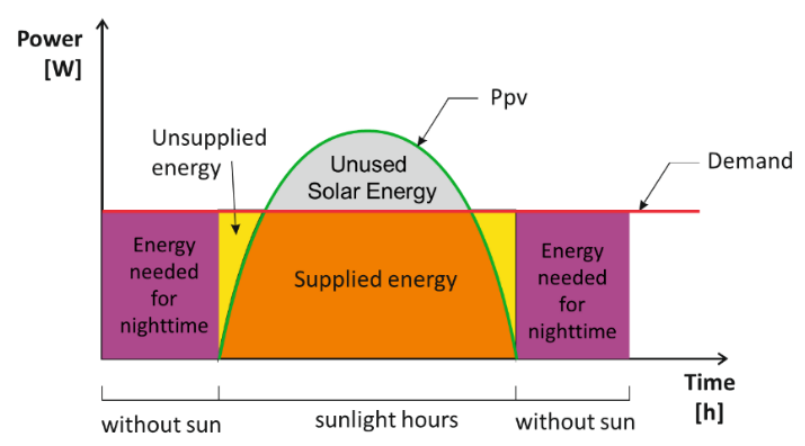

Fig. 1. Available solar power and energy demand.

\section{Energy parameters}

Solar power

The available solar power for electricity production depends on solar irradiance and the photovoltaic array size.

$\mathrm{P}_{\mathrm{S}}=\mathrm{I}_{\mathrm{s}} \cdot \mathrm{A}$

$\mathrm{P}_{\mathrm{S}} \quad$ solar power $[\mathrm{W}]$

$\mathrm{I}_{\mathrm{s}} \quad$ solar irradiance $\left[\mathrm{W} / \mathrm{m}^{2}\right]$

A area of the photovoltaic array $\left[\mathrm{m}^{2}\right]$

The integral of the solar power over time results in the available solar energy $[\mathrm{J}]$ :

$\dot{\mathrm{E}}_{\mathrm{s}}=\int \mathrm{P}_{\mathrm{s}} \mathrm{dt}$

$\dot{\mathrm{E}}_{S} \quad$ solar energy [J]

$\mathrm{P}_{\mathrm{s}} \quad$ solar power [W]

$\mathrm{t}$ time

Efficiency of the photovoltaic array

Energy factor that depends on the type of PV panel used and the electric losses through PV panels interconnections.

$\eta_{\mathrm{pv}}=\frac{\mathrm{P}_{\mathrm{pv}}}{\mathrm{Ps}}$

$\eta_{\mathrm{pv}}$ efficiency of the photovoltaic array [W/W]

$\mathrm{P}_{\mathrm{pv}}$ photovoltaic power [W]

$\mathrm{P}_{\mathrm{S}} \quad$ solar power $[\mathrm{W}]$

Demand

Electric power consumed by the electric load [W].

Consumption

Electricity consumed by the electric load in $[\mathrm{J}]$ or $[\mathrm{W} h]$.

$\dot{\mathrm{E}}_{l}=\int \mathrm{P}_{1} \mathrm{dt}$

$\dot{\mathrm{E}}_{l}$ consumption[W h]

$\mathrm{P}_{1}$ demand[W]

$\mathrm{t}$ time[s]

Demand during daylight hours

Electric power that has to be supplied by the PV system immediately after production during daylight hours.

$\mathrm{P}_{\mathrm{sh}}=\sum P$, if $\left\{\begin{array}{l}P_{P V}>0 ; P=P_{l} \\ P_{P V}<0 ; P=0\end{array}\right\}$

$\mathrm{P}_{\mathrm{sh}}$ demand in daylight hours [W]

$\mathrm{P}_{1}$ demand [W]

$\mathrm{P}_{\mathrm{pv}}$ photovoltaic power [W]

Demand out of daylight hours 
Electric power that has to be supplied out of daylight hours. Since energy storage is not considered, this electricity demand cannot be fulfilled by the PV system.

$\mathrm{P}_{\mathrm{wsh}}=\sum P$, if $\left\{\begin{array}{l}P_{P V}>0 ; P=P_{l} \\ P_{P V}<0 ; P=0\end{array}\right\}$

$\mathrm{P}_{\mathrm{wsh}}$ demand out of daylight hours $[\mathrm{W}]$

$\mathrm{P}_{1}$ demand [W]

$\mathrm{P}_{\mathrm{pv}}$ photovoltaic power [W]

\section{Supplied energy}

Electricity supplied by the PV system during daylight hours.

$\mathrm{E}_{\mathrm{SUP}}=\sum P$, if $\left\{\begin{array}{c}P_{P V}>P_{l} ; P=P_{l} \cdot \Delta t \\ P_{P V}<P_{l} ; P=P_{P V} \cdot \Delta t\end{array}\right\}$

$\mathrm{E}_{\text {SUP }}$ supplied energy $[\mathrm{J}]$

$\mathrm{P}_{1}$ demand [W]

$\mathrm{P}_{\mathrm{pv}}$ photovoltaic power [W]

$\Delta t \quad$ time interval for integration $[\mathrm{s}]$

Unsupplied energy

Electricity not supplied by the PV system.

$\mathrm{E}_{\mathrm{USUP}}=\sum P$, if $\left\{\begin{array}{l}P_{P V}<P_{l} ; P=\left(P_{l}-P_{P V}\right) \cdot \Delta t \\ P_{P V}>P_{l} ; P=0\end{array}\right\}$

$\mathrm{E}_{\text {USUP }} \quad$ unsupplied power [J]

$\mathrm{P}_{1}$ demand [W]

$\mathrm{P}_{\mathrm{pv}}$ photovoltaic power [W]

$\Delta t \quad$ time interval for integration $[\mathrm{s}]$

Unused solar energy

Solar energy that is not used or harnessed. Depending on local legislation, this energy can be injected (sold) to the public electric grid.

$\mathrm{E}_{\mathrm{USE}}=\sum P$, if $\left\{\begin{array}{l}P_{P V}>P_{l} ; P=\left(P_{P V}-P_{l}\right) \cdot \Delta t \\ P_{P V}<P_{l} ; P=0\end{array}\right\}$

$\mathrm{E}_{\mathrm{USE}}$ unused solar energy $[\mathrm{J}]$

$\mathrm{P}_{1} \quad$ electric load power [W]

$\mathrm{P}_{\mathrm{pv}} \quad$ photovoltaic array power [W]

\section{Financial assessment}

Payback period for the PV system

Time needed to recover the investment cost of the complete PV system by saving the cost that would have been induced by buying the electricity from the public grid.

$P_{\mathrm{p}, \mathrm{si}}=\frac{S P P+E A}{S P}$

$\mathrm{P}_{\mathrm{p}, \mathrm{si}}$ Payback period for the PV system [year]

$S P P$ solar power plant cost [USD]

EA electric accessories cost [USD]

SP supplied power cost [USD]

Payback period for the PV system with energy sale

Time needed to recover the investment cost of the complete PV system by saving the cost that would have been induced by buying the electricity from the public grid and by selling the unused solar-generated electricity. $\mathrm{P}_{\mathrm{p}, \mathrm{si}+\mathrm{es}}=\frac{S P P+E A}{S P+U S P}$

$\mathrm{P}_{\mathrm{p}, \mathrm{si}+\mathrm{si}}$ Payback period for the PV system with energy sale [year]
SPP solar power plant cost [USD]

EA electric accessories cost [USD]

SP supplied power cost [USD]

USP unused solar power (sale) [USD]

The analyzed uncertainties are shown in Table 1. The measurement instruments and equipment used for this study were conventional and widely used in the industry.

Table 1. Uncertainties. $\delta$

\begin{tabular}{lll}
\hline Parameter & $\delta, \%$ & Reference \\
\hline Solar irradiance & 0.5 & Instrument \\
Solar irradiation & 0.5 & {$\left[\left(\frac{\delta \mathrm{t}}{\mathrm{t}}\right)^{2}+\left(\frac{\delta \mathrm{I}_{\mathrm{s}}}{\mathrm{I}_{\mathrm{s}}}\right)^{2}\right]^{0.5}$} \\
Solar power & 0.6 & {$\left[\left(\frac{\delta \mathrm{A}}{\mathrm{A}}\right)^{2}+\left(\frac{\delta \mathrm{I}_{\mathrm{s}}}{\mathrm{I}_{\mathrm{s}}}\right)^{2}\right]^{0.5}$} \\
PV array power & 0.5 & {$\left[\left(\frac{\delta \mathrm{A}}{\mathrm{A}}\right)^{2}+\left(\frac{\delta \mathrm{I}_{\mathrm{s}}}{\mathrm{I}_{\mathrm{s}}}\right)^{2}\right]^{0.5}$} \\
$\begin{array}{l}\text { Demand } \\
\text { Consumption }\end{array}$ & 2.2 & {$\left[\left(\frac{\delta \mathrm{P}}{\mathrm{P}}\right)^{2}+\left(\frac{\delta \mathrm{t}}{t}\right)^{2}\right]^{0.5}$} \\
$\begin{array}{l}\text { Supplied Power } \\
\text { Unsupplied Power } \\
\text { Solar Power Loss }\end{array}$ & 2.2 & {$\left[\left(\frac{\delta \mathrm{P}}{\mathrm{P}}\right)^{2}+\left(\frac{\delta \mathrm{t}}{t}\right)^{2}\right]^{0.5}$} \\
\hline
\end{tabular}

\section{Dynamic simulation and financial assessment}

In order to validate the technology, historical data from a typical residential building was used. The building had, besides of residential apartments, business offices, a sports field and a gym. The monthly cost of peak and out of peak periods was obtained from the electricity bills (Table 2). The detailed energy consumption was not available in the documentation, so it was measured.

Table 2. Demand and consumption of the electric load.

\begin{tabular}{ll}
\hline Parameter & Value \\
\hline Consumption out of peak hours & $12 \mathrm{MW} \cdot \mathrm{h}$ \\
Consumption during peak hours & $4.8 \mathrm{MW} \cdot \mathrm{h}$ \\
Demand out of peak hours & $48 \mathrm{~kW}$ \\
Demand during peak hours & $55 \mathrm{~kW}$ \\
Energy during daylight hours/total energy & 0.48 \\
\hline
\end{tabular}

The energy demand for June 2018 is shown in Fig. 2, as an example. The demand varies from $5 \mathrm{~kW}$ to $65 \mathrm{~kW}$, which indicates a high dispersion in electricity consumption.

Fig. 3 represents the hourly energy demand. It shows that the highest consumption occurs between $8 \mathrm{~h}$ and $23 \mathrm{~h}$, mainly due to the kind of activities performed in the building. The consumption during this period of the day is between $30 \mathrm{~kW}$ and $60 \mathrm{~kW}$. This information is relevant for the definition of the kind of photovoltaic system that will be installed. The Figure shows that the consumption during sunlight hours does not exceed 40 $\mathrm{kW}$. This value is different than the average that could be calculated with the conventional method. In this case, the maximum consumption occurs during nighttime. 


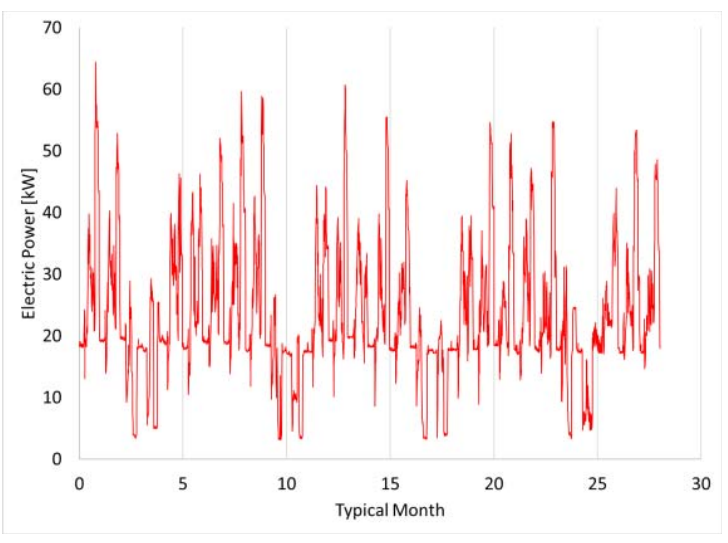

Fig. 2. Demand in June 2018.

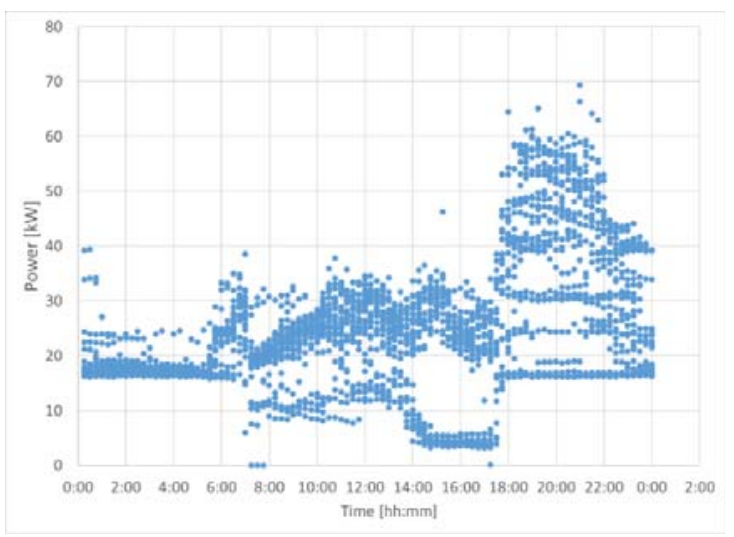

Fig. 3. Hourly energy consumption, June 2018.

The same dispersion is observed in the analysis of the solar energy potential. Solar radiation values for June are shown in Fig. 4. The granularity of this information does allow for the estimation of the energy potential and the electricity generation [13], nevertheless, reducing this data to one only value (yearly-monthly average) is not appropriate for PV systems dimensioning.

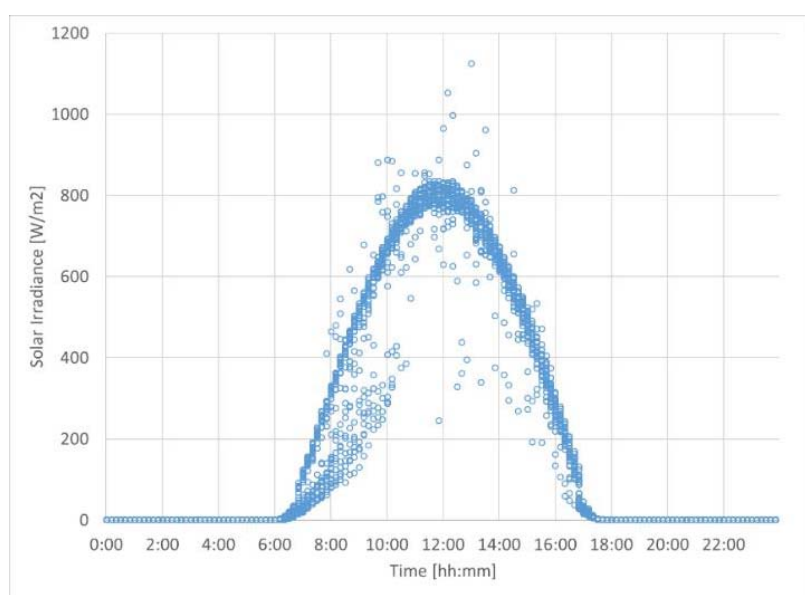

Fig. 4. Solar irradiance, typical month, June 2018.

When obtaining monthly-hour averages (in solar power and electricity demand) and considering, for example, a peak installed power of $30 \mathrm{~kW}$ and a photovoltaic array efficiency of 0.10 , the uncertainty reaches higher relative values of approximately $40 \%$ (Fig. 5). When calculating the energy supply (also Fig. 5), the error margin is considerable and not adapted to dimensioning. In financial terms, this error does not to guarantee a correct utilization and harnessing of the solar technology.

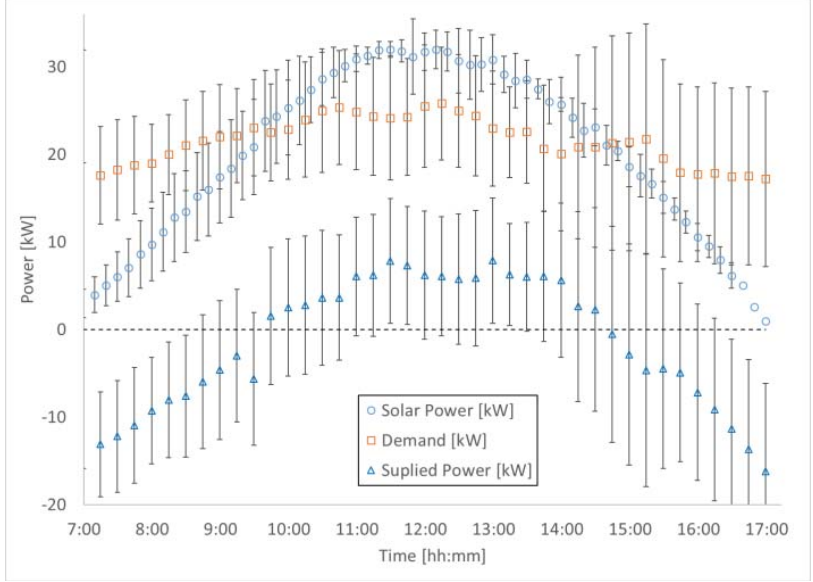

Fig. 5. Solar power, demand and power supply, June 2018.

Using equations from (4) to (9), the important variables for analysis are determined (power and energy). Then, the energy coupling is performed. A sample of this process is shown in Fig. 6. Demand, solar power, supplied energy and unsupplied energy are shown. The energy values are integrated in the time interval established during a defined period. This methodology is applied in a Microsoft Excel ${ }^{\circledR}$ sheet. In this study case, the energy integration (solar power and electricity demand) was performed in 15 minutes intervals during the whole year of 2018. The simulation is performed for different PV power plant sizes to identify the scenario that better satisfies the demand and diminishes the unused solar power.

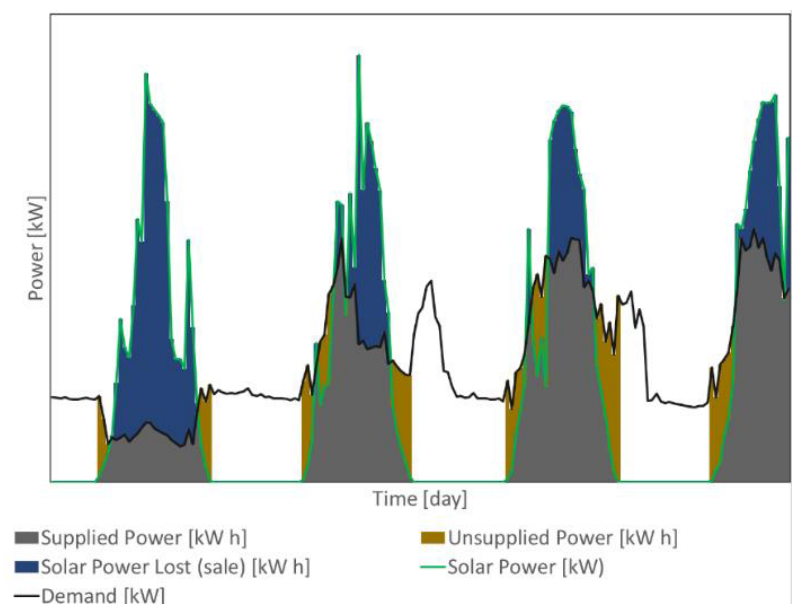

Fig. 6. Example of energy coupling.

The results of the simulation are shown in Fig. 7, Fig. 8 and Fig. 9, for PV power pkants of $20 \mathrm{~kW}, 30 \mathrm{~kW}$ and $50 \mathrm{~kW}$, respectively. Due to the quantity of data obtained, only some days of the year are shown. The energy 
balance is performed in intervals of 15 minutes, during a year (in this case). It is observed that the error propagation is drastically diminished to $2.2 \%$ (see uncertainties table). To determine the optimal PV power plant size to be installed, it is necessary to perform an energy balance for all the period. Integrating power over time, the energy values are obtained (the supplied energy, the unsupplied energy and the unused energy) for every plant size.

Fig. 7, Fig. 8 and Fig. 9 show three graphics each. The upper shows the variation of solar power and

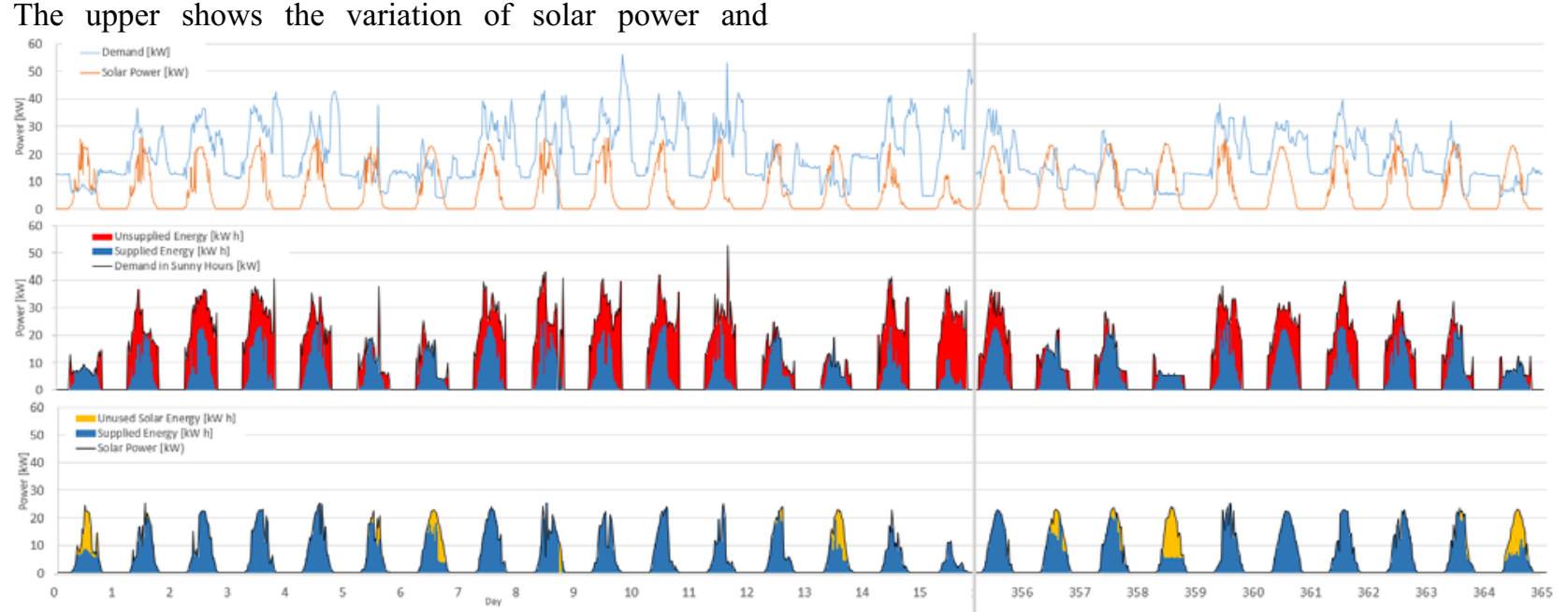

Fig. 7. Energy coupling for a $20 \mathrm{~kW} \mathrm{PV} \mathrm{power} \mathrm{plant.}$

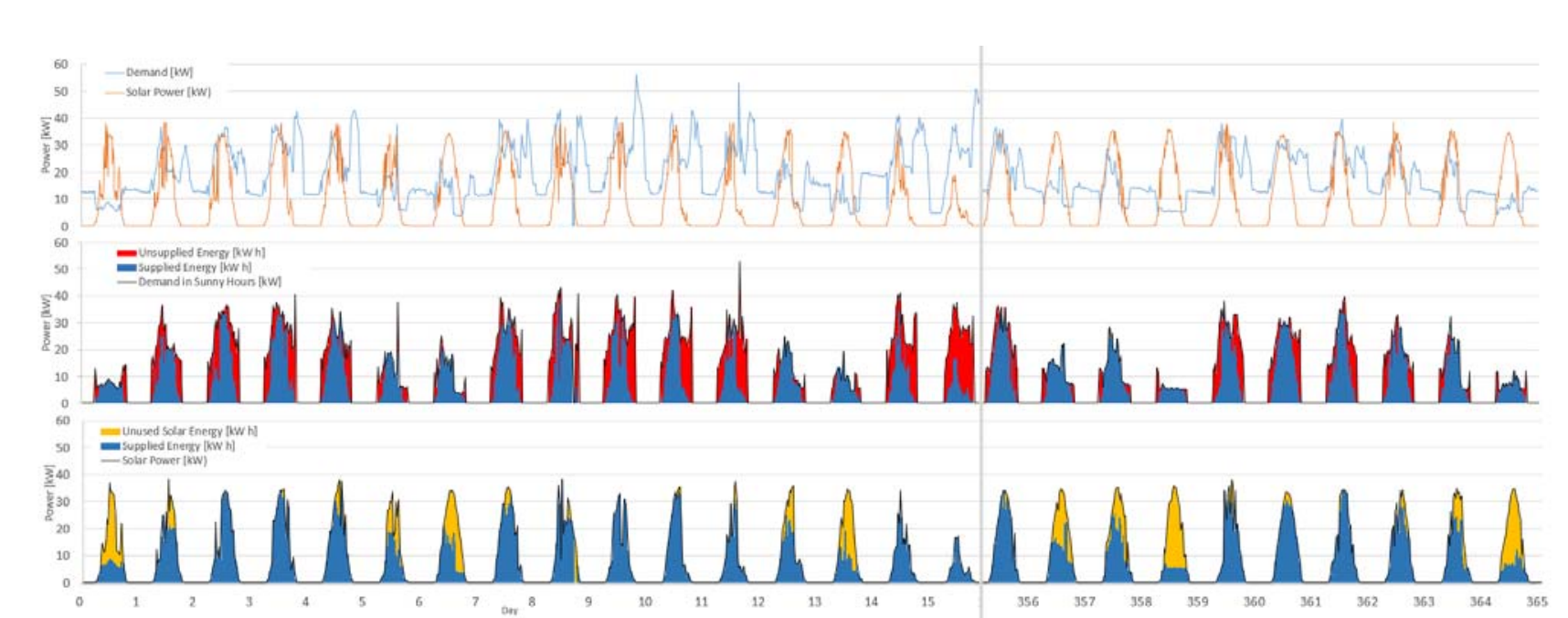

Fig. 8. Energy coupling for a $30 \mathrm{~kW}$ PV power plant.

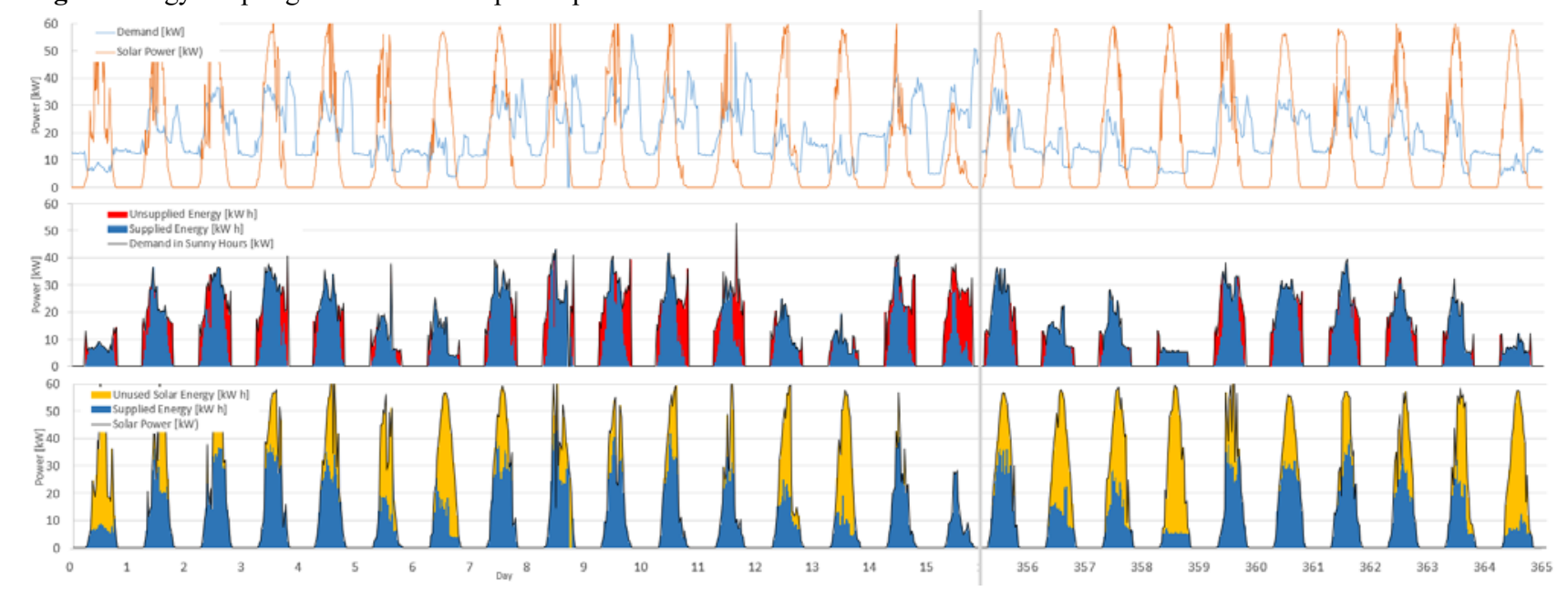

demand, the one in the middle shows demand, supplied energy and unsupplied energy. The lower shows the solar power, the supplied energy and the unused energy.

It can be seen that when the installed solar power is increased, the supplied energy (red area) increases as well, the unsupplied energy (blue area) diminishes and the unused solar energy (yellow area) increases.

In order to define the most appropriate solar power for an installation, it is necessary to reduce the unsupplied and the unused energy. 
Fig. 9. Energy coupling for a $50 \mathrm{~kW}$ PV power plant.

For the financial assessment, the following values are taken into account:

SPP

EA

$755 \mathrm{USD} / \mathrm{kW}$

$0.35 * \mathrm{SPP}$

Cost of the electricity from the grid $\quad 0.071 \mathrm{USD} / \mathrm{kW} \cdot \mathrm{h}$

The energy (and financial) balance is shown in Fig. 10. The percentages of supplied and unused energy are shown for every PV power plant size. Fig. 10 also shows the percentage of the costs of supplied and unsupplied energy.

Fig. 10 constitutes a tool that can be used by the solar PV system designer as an aid for dimensioning. In this study case, it is observed that the most appropriate solar plant size is between 30 and $60 \mathrm{~kW}$. For plant sizes from 50 to $60 \mathrm{~kW}$, the supplied energy percentage is almost constant and the unused energy percentage increases, which can be a determining factor to discard the $60 \mathrm{~kW}$ PV plant.

It is also observed that the main and the secondary vertical axis are equivalent, but are in different units (cost and energy, respectively). Thus, this graphic provides important information that can aid for a right decision.

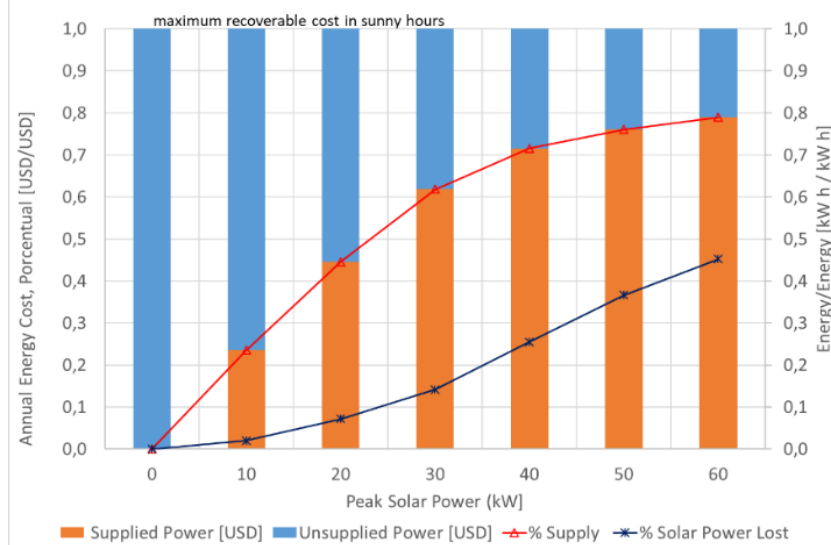

Fig. 10. Energy and financial assessment summary.

Concerning the financial assessment, Fig. 11 shows the payback period for the investment for the different PV power plant sizes. Two scenarios are considered: sale of the unused energy and the loss of the unused energy. This information is important, not only to analyze if the investment is feasible, but also to decide of the location of the solar power plant, since it would have to be close to sites where the connection to the electric grid for energy sale is allowed or there is a project for it.

It can be observed that for the studied PV power plant sizes, the payback period is almost constant when energy sale is considered, but otherwise, it increases.

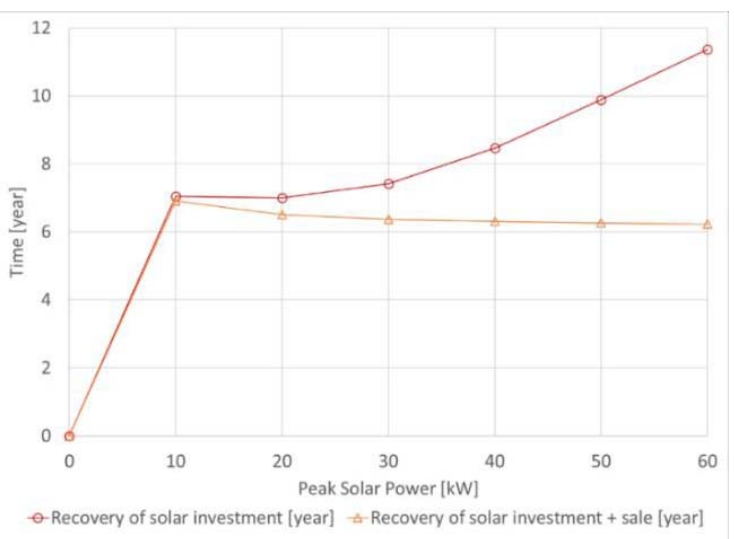

Fig. 11. Payback period for different PV power plants sizes, with and without energy sale.

\section{Conclusions}

A reliable methodology for photovoltaic systems dimensioning has been presented in this article. Technical-financial variables that provide an aid for the dimensioning of photovoltaic projects have been presented.

The proposed methodology considers the typical energy potential of a region and the detailed characteristics of the electric load. Both parameters are matched to different solar plant sizes and analyzed during a period that guarantees the reliability of the results.

The energy coupling is performed integrating the power (PV system and electric load) in short time intervals to determine the supplied energy, the unsupplied energy and the unused energy.

The daily integration of these three factors (through a dynamic simulation and financial assessment), determines the most appropriate PV plant size for every undertaking.

The results show that this methodology reduces the uncertainty of the fulfillment of the demand, hence increasing the reliability of financial estimations that allow the choice of the most appropriate PV plant size.

\section{Acknowledgement}

This project was sponsored by the RED CYTED 717RTO535 - STORAGE OF SOLAR ENERGY FOR ISOLATED COMMUNITIES - AESCA.

\section{References}

1. Khatib T., Ibrahim I. A., Mohamed A. A review on sizing methodologies of photovoltaic array and storage battery in a standalone photovoltaic system. Energy Convers. Manag., 2016; vol. 120, pp. 430448.

2. Hernández-Callejo L., Gallardo-Saavedra S., AlonsoGómez V. A review of photovoltaic systems: Design, operation and maintenance. Sol. Energy, 2019; vol. 188, pp. 426-440. 
3. Talavera D. L., Muñoz-Rodriguez F. J., JimenezCastillo G., Rus-Casas C. A new approach to sizing the photovoltaic generator in self-consumption systems based on cost-competitiveness, maximizing direct self-consumption. Renew. Energy, 2019; vol. 130, pp. 1021-1035.

4. Ghaib K., Ben-Fares F. Z. A design methodology of stand-alone photovoltaic power systems for rural electrification. Energy Convers. Manag.; 2017; vol. 148, pp. 1127-1141.

5. Tsianikas S., Zhou J., Birnie D. P., Coit D. W. Economic trends and comparisons for optimizing grid-outage resilient photovoltaic and battery systems. Appl. Energy, 2019; vol. 256, p. 113892.

6. Xu G., Shang C., Fan S., Zhang X., Cheng H. Sizing battery energy storage systems for industrial customers with photovoltaic power. Energy Procedia, 2019; vol. 158, pp. 4953-4958.

7. Zhang J., Cho H., Luck R., Mago P. J. Integrated photovoltaic and battery energy storage (PV-BES) systems: An analysis of existing financial incentive policies in the US. Appl. Energy, 2018; vol. 212, pp. 895-908.

8. Benavente F., Lundblad A., Campana P. E., Zhang Y., Cabrera S., Lindbergh G. Photovoltaic/battery system sizing for rural electrification in Bolivia: Considering the suppressed demand effect. Appl. Energy, 2019; vol. 235, pp. 519-528.

9. Ayop R., Isa N. M., Tan C. W. Components sizing of photovoltaic stand-alone system based on loss of power supply probability. Renew. Sustain. Energy Rev., 2018; vol. 81, pp. 2731-2743.

10. Roberts M. B., Bruce A., MacGill I. Impact of shared battery energy storage systems on photovoltaic selfconsumption and electricity bills in apartment buildings. Appl. Energy, 2019; vol. 245, pp. 78-95.

11. Li J. Optimal sizing of grid-connected photovoltaic battery systems for residential houses in Australia. Renew. Energy, 2019; vol. 136, pp. 1245-1254.

12. Koutroulis E., Kolokotsa D., Potirakis A., Kalaitzakis K. Methodology for optimal sizing of stand-alone photovoltaic/wind-generator systems using genetic algorithms. Sol. Energy, 2006; vol. 80, no. 9, pp. 1072-1088.

13. Khan F. A., Pal N., Saeed S. H. Review of solar photovoltaic and wind hybrid energy systems for sizing strategies optimization techniques and cost analysis methodologies. Renew. Sustain. Energy Rev., 2018; vol. 92, pp. 937-947.

14. Behravesh V., Foroud A. A., Keypour R. Optimal sizing methodology for photovoltaic and wind hybrid rooftop generation systems in residential low voltage distribution networks. Sol. Energy, 2018; vol. 173, pp. 17-33.

15. Khiareddine A., Ben Salah C., Rekioua D., Mimouni M. F. Sizing methodology for hybrid photovoltaic /wind/ hydrogen/battery integrated to energy management strategy for pumping system. Energy, 2018; vol. 153, pp. 743-762.

16. Coppitters D., De Paepe W., Contino F. Surrogateassisted robust design optimization and global sensitivity analysis of a directly coupled photovoltaic-electrolyzer system under technoeconomic uncertainty. Appl. Energy, 2019; vol. 248, pp. 310-320.

17. Rawat R., Kaushik S. C., Lamba R. A review on modeling, design methodology and size optimization of photovoltaic based water pumping, standalone and grid connected system. Renew. Sustain. Energy Rev., 2016; vol. 57, pp. 1506-1519.

18. Peralta Vera A. A., Del Carpio Beltrán H. J., Zúñiga Torres J. C., Milón Guzmán J. J., Braga S. L. Experimental Study of a Photovoltaic Direct Current Water Pumping System for Irrigation in RuralIsolated Region of Arequipa, Peru. J. Sol. Energy Eng. Trans. ASME, 2019; vol. 141, no. 4.

19. Rosas-Flores J. A., Zenón-Olvera E., Gálvez D. M. Potential energy saving in urban and rural households of Mexico with solar photovoltaic systems using geographical information system. Renew. Sustain. Energy Rev., 2019; vol. 116, p. 109412.

20. Toroghi S. H., Oliver M. E. Framework for estimation of the direct rebound effect for residential photovoltaic systems. Appl. Energy, 2019; vol. 251, p. 113391.

21. Bailera M., Peña B., Lisbona P., Romeo L. M. Decision-making methodology for managing photovoltaic surplus electricity through Power to Gas: Combined heat and power in urban buildings. Appl. Energy, 2018; vol. 228, pp. 1032-1045. 